\title{
REMINERALIZING EFFECT OF NANOHYDROXYAPATITE TOOTHPASTE ON CARIES- LIKE LESIONS IN PRIMARY TEETH (AN IN VITRO STUDY)
}

\author{
Sally S. Sultan ${ }^{1 *}$ BDS, Ahmed A. Mohamed ${ }^{2}$ PhD, Reham S. Soliman ${ }^{3}$ \\ $\mathrm{PhD}$, Sara A. Hamza ${ }^{4} \mathrm{PhD}$
}

\begin{abstract}
OBJECTIVES: To evaluate in vitro, the effect of nano-hydroxyapatite (NHA) toothpaste in comparison with a fluoridated toothpaste on remineralization of caries like lesion in the enamel of primary teeth.

MATERIALS AND METHODS: sixty sound primary anterior teeth were coated with nail varnish; leaving squares of 3x3 mm on facial surface uncovered. Forty teeth were divided into two groups where group (I) $n=20$ treated by NHA toothpaste and group (II) $n=20$ treated by fluoridated toothpaste containing sodium monofluorophosphate (1450 ppm F). They were examined with Vickers Microhardness device. The remaining 20 teeth were divided into two groups (III and IV). They were sectioned longitudinally in a labiolingual direction into two equal halves, mesial half not treated (sub group IIIA) and distal half treated by NHA (sub group IIIB). Mesial half not treated (sub group IVA) and distal half treated by fluoridated toothpaste (sub group IVB). Specimens were evaluated quantitatively and qualitatively with Polarized Light Microscope.

RESULTS: The microhardness of teeth significantly decreased following acid exposure but increased again in both groups after exposure to toothpastes. The NHA toothpaste non-significantly increased the percent change of microhardness by 1.65 times than fluoridated toothpaste $(\mathrm{p}=0.06)$. The percent differences in lesion depth between test group IIIB and its control group IIIA was $-58.96 \pm 9.04$, whereas between test group IVB and its control IVA was $-56.26 \pm 17.43$. There was no statistically significant difference between the two values $(\mathrm{P}=0.67)$.

CONCLUSION: NHA and fluoridated toothpastes are equally effective as remineralizing materials for the enamel.

KEYWORDS: Nano hydroxyapatite, Remineralization, fluoride, Primary teeth.
\end{abstract}

1- Dentist at the Egyptian Health Insurance, Alexandria, Egypt.

2- Professor of Pediatric Dentistry and Dental Public Health, Faculty of Dentistry, Alexandria University, Alexandria, Egypt.

3- Lecturer of Pediatric Dentistry, Faculty of Dentistry, Alexandria University, Alexandria, Egypt.

4- Lecturer of Oral Biology, Faculty of Dentistry, Alexandria University, Alexandria, Egypt.

*Corresponding author:

E-mail: sallysirag@gmail.com

\section{INTRODUCTION}

Dental caries is a chronic, slowly progressing disease, which is considered a significant problem across the world. It occurs as an interaction between the tooth surface, dental biofilm and fermentable carbohydrates (1). It is a dynamically alternating process of demineralization and remineralization. The remineralization process (the replacement of lost minerals in hard dental tissues) can halt, slow down, and, in some cases, reverse the caries process (2).

Fluoride has been widely recommended as an agent for preventing early enamel carious lesions (3). The process by which fluoride improves caries resistance may result from both systemic and topical fluoride applications and may be categorized into: increasing enamel resistance, increasing maturation rate, remineralization of incipient caries, interfering with microorganism and improving morphology of the tooth. Such cariostatic therapeutic effects are inadequate to deal with high caries risk patients (4). But promising remineralization effects are possible using high fluoride concentration agents (5).
The mineral-crystalline type of calcium and phosphorus present in enamel, dentin, cement, and bone is hydroxyapatite. Due to its optimal properties, such as similarity to the mineral composition of hard tissues, biocompatibility, and low solubility, it is commonly used in biology, medicine, and dentistry. When added to tooth enamel, it has remineralizing effects (6). Advances in nanotechnology have allowed for smaller particle size and shape modifications hence producing bioactive calcium phosphate compounds with high potential for penetration into the demineralized surface porosities (7). Nano hydroxyapatite (NHA) has a higher surface/volume ratio and is more effective than large hydroxyapatite particles (8).

Previous studies evaluated the influence of NHA solution on erosive enamel lesions of permanent human teeth and confirmed that these lesions may be repaired by NHA (9). Nanohydroxyapatite toothpastes and mouthwashes have also been shown to be able to remineralize initial enamel caries (10).

Thus, the present study aimed at assessing and comparing the remineralizing effects of NHA and 
fluoridated toothpaste on artificially created carious lesions in primary anterior teeth by measuring surface microhardness and lesion depth using the polarized light microscope. The null hypothesis is that a toothpaste containing NHA will have similar effect of remineralization as that of fluoridated toothpaste.

\section{MATERIALS AND METHODS}

This in vitro experimental study was approved by the ethics committee in the Faculty of Dentistry Alexandria University. The minimal sample size was calculated based on a previous study (10). A sample size of 20 teeth per group (number of groups $=2$ ) (total sample size $=40$ teeth) is the enough required sample size (11) as statistically significant with $80 \%$ power $(\beta=20 \%)$ and at a significance level of $95 \%(\alpha=0.05)$ (12). Sample size per group does not need to be increased to control for attrition bias (13). Twenty teeth will be included in the study for histological part of the study. The sample power size was calculated using GPower version 3.1.9.2 (14).

Sixty human sound primary anterior teeth (sound, exfoliated or extracted for orthodontic purpose) were collected from the clinic of the Department of Pediatric Dentistry and Dental Public Health in Faculty of Dentistry, Alexandria University and examined visually to ensure they meet the inclusion criteria of having no caries or previous fillings and no developmental anomalies and by a magnifying lens for the absence of any cracks. The teeth were stored in saline solution at room temperature till required for use (10). The teeth were randomly allocated using a computer-generated list of random numbers to one of the two treatment groups (15). A flow chart of the study design is shown in (Figure 1).

\section{Sample preparation}

The teeth were cleaned with fluoride free pumice then washed with distilled water and air-dried. A $3 \times 3 \mathrm{~mm}$ square of self-adhesive tape was stuck above the CEJ of the labial surface of each tooth. All the teeth surfaces were coated with acid-proof nail varnish (10). When the nail varnish dried the self-adhesive tapes were removed leaving only a window of $3 \times 3 \mathrm{~mm}$ exposed enamel on labial surface of the anterior primary teeth (16). Each tooth was mounted in a self-cure acrylic resin inside a cylindrical plastic mold with its labial surface facing upwards (17). Twenty blocks were longitudinally sectioned (after demineralization and caries lesion formation) in a labiolingual direction through the center of the window of tooth with a diamond disc mounted on a straight hand piece to obtain two equal halves where each half was considered as a specimen. Each two halves were kept together in a separate container,_as distal half was treated with the specific anticariogenic agent (subgroup IIIB and IVB) and the mesial half remained untreated and served as control (group IIIA and IVA) (18). All the specimens were re-coated with nail varnish to cover any surface that has been exposed due to sectioning as well as the cut surface (15).

\section{Grouping and Methods}

Group I: Consisted of 20 primary teeth labeled from (1-20) were treated with NHA toothpaste (Carefree CTx3 gel, Canada). Group II: Consisted of 20 primary teeth labeled from (21-40) were treated with fluoridated toothpaste (Signal toothpaste cavity fighter which contained sodium monofluorophosphate $1450 \mathrm{ppm}$ F).

The remaining twenty primary teeth were randomly assigned into two groups. Group III: Consisted of 10 teeth which were longitudinally sectioned into two halves. Subgroup IIIA $(n=10)$ the mesial half was not treated with toothpaste and subgroup IIIB $(n=10)$ the distal half was treated with NHA toothpaste. Group IV: Consisted of 10 teeth which were longitudinally sectioned into two halves. Subgroup IVA $(n=10)$ the mesial half was not treated with toothpaste and subgroup IVB $(n=10)$ the distal half was treated with fluoridated toothpaste.

\section{Artificial carious lesion formation}

The teeth in groups (I, II) (after the baseline microhardness was measured) and all the specimens of groups (III, IV) were immersed in a demineralizing solution before sectioning (50 $\mathrm{mM}\left(\mathrm{CH}_{3} \mathrm{COOH}\right), 2.2 \mathrm{mM}\left(\mathrm{Ca}\left(\mathrm{NO}_{3}\right) 2.2 \mathrm{H}_{2} \mathrm{O}\right), 2.2 \mathrm{mM}$ $\left(\mathrm{KH}_{2} \mathrm{PO}_{4}\right), 0.1 \mathrm{ppm}(\mathrm{NaF})$ and $(\mathrm{NaOH})$ was used to adjust the $\mathrm{pH}$ to 4.2$) 10 \mathrm{ml} /$ tooth at $37^{\circ} \mathrm{C}$ for 96 hours without stirring (19). Demineralizing solution was prepared at the lab of Faculty of Pharmacy, Alexandria University.

\section{Application of toothpastes}

All the teeth were brushed manually using a soft tooth-brush with the toothpaste applied for 30 cycles using a pea-sized amount of toothpaste. Each brushing cycle lasted for 15 seconds during which the teeth were immersed in slurry water made of the respective toothpaste (10). The slurry was prepared daily before application by mixing toothpaste and deionized water in the ratio of 1:3 (20). The teeth were brushed twice daily and stored in artificial saliva until the following day for 15 days (10).

\section{Microhardness test evaluation}

Teeth in groups (I, II) were examined with Vickers Microhardness Device (Wilson microhardness tester, Japan) with a load of $25 \mathrm{gm}$ for 5 seconds. Three indentations were made in the enamel surface of each specimen then the mean was calculated and considered as the hardness number of the tooth (21). Microhardness testing was done before any cariogenic challenge (initial base line assessment), after initial caries formation (second assessment) and at the end of the study (final assessment).

\section{Polarized light microscopic evaluation}

The specimens from each test group (IIIB, IVB) and their corresponding controls (IIIA, IVA) $(n=40)$ were prepared for analysis by polarized light microscope (Olympus America Inc.). Longitudinal ground sections of about 15 $\mu \mathrm{m}$ thickness were prepared, and then mounted using Canada balsam to hold the specimen in place between the slip cover and the glass slide. Depth measurements were done using (image J.46) software (22). The mean depth of the enamel lesion of each specimen was measured by averaging of three lines: one at each side and one at the center of the lesion within the subsurface of the lesion body, perpendicular to the outer layer of the enamel surface and extending to the translucent band (Figure 2).

\section{Statistical analysis}

Data were analyzed by the use of IBM SPSS for Windows version 23.0 (IBM Corp., Armonk, N.Y., USA). Data were reviewed to check for any errors during data entry. Normality was checked using tests of normality. All 
variables showed normal distribution, so means and standard deviations (SD) were calculated. Percent change in microhardness was calculated using the following equation:

Microhardness after tooth paste use - Microhardness after demineralization X100 Microhardness after demineralization

(23).

Simple linear regression was used for determining the effect of toothpaste type on percent change in microhardness adjusted for baseline microhardness values. Paired t-test was used for comparing lesion depth in the treated and untreated parts of the same tooth in each group.

Percent change in lesion depth was calculated for each group using the following equation $\frac{\text { Depth in treated side }- \text { Depth in untreated side }}{\text { lesion depth in untreated side }}$ X10

(23) and compared in the 2 groups using independent samples t-test. Significance was set at $P \leq 0.05$.

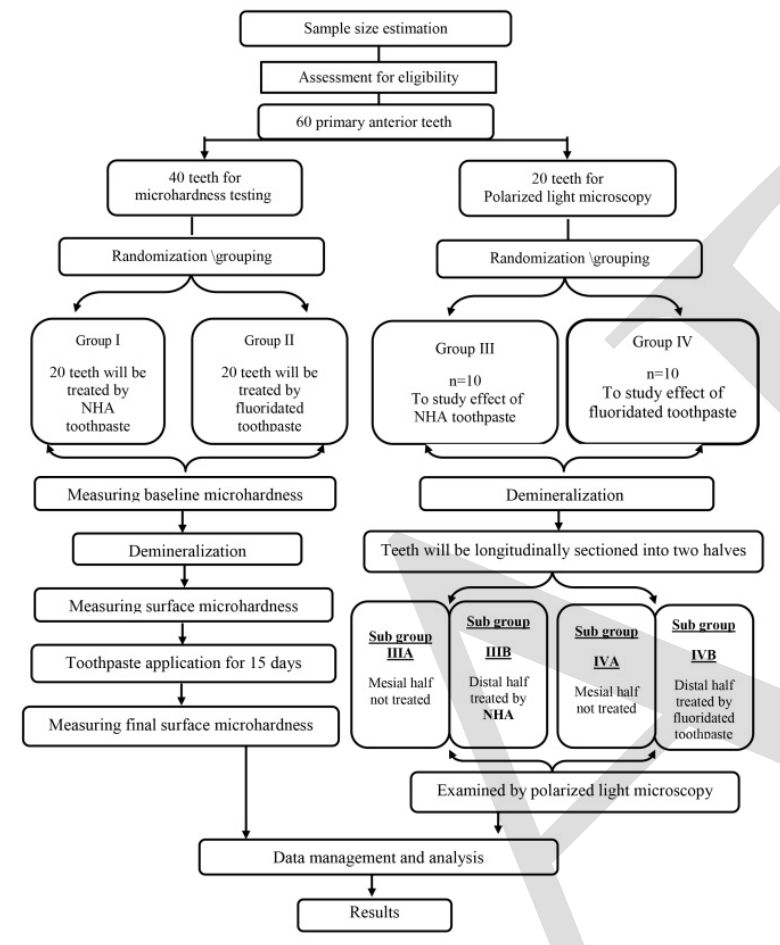

Figure 1: A flow chart of study design

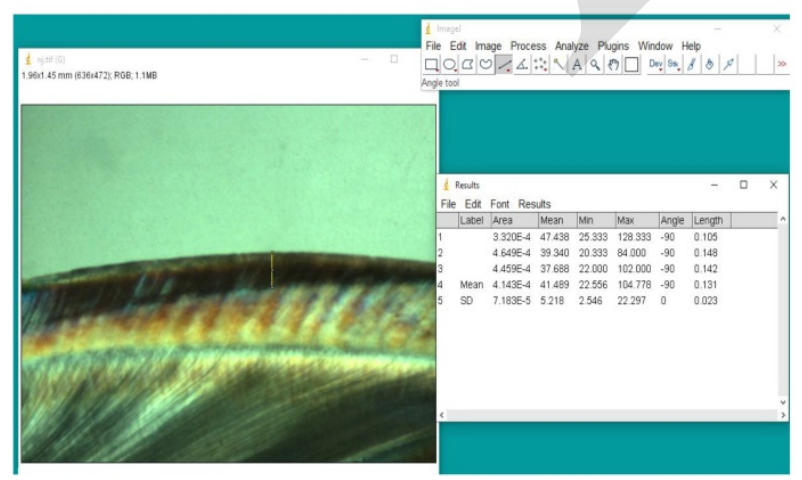

Figure 2: Transmitted light photomicrographs showing the use of (image J) software to measure the lesion depth, magnification $\mathrm{X} 40$.The mean depth of the 3 points of enamel lesion.

\section{RESULTS}

Surface microhardness (mean \pm SD) values of the teeth are shown in (Table 1). The mean microhardness at baseline in group I and II were $286.47 \pm 29.12$ and $285.78 \pm 27.55$ respectively which decreased to $257.85 \pm 29.01$ and $257.13 \pm 29.77$ after demineralization and increased again to $277.45 \pm 27.85$ and $272.43 \pm 26.53$ after toothpaste application for 15 days. Percent change in microhardness after toothpaste application and demineralization in group I and II after adjusting baseline microhardness values showed that group I (NHA toothpaste) is 1.65 times higher than that of group II (fluoridated toothpaste) and the difference was not significant $(P=0.06)$. Adjusted mean for percent change in microhardness in group I (NHA toothpaste) was 7.80 and for group II (Fluoridated toothpaste) was 6.16, which was higher for NHA toothpaste (Table 2).

The mean lesion depth of subgroup IIIA (control) was $191.70 \pm 50.87 \mu \mathrm{m}$, whereas in subgroup IIIB (test) was $77.30 \pm 22.61 \mu \mathrm{m}$. There was a decrease in lesion depth in subgroup IIIB and the difference was statistically significant $(P<0.001)$. The mean lesion depth of subgroup IVA was $172.30 \pm 57.28 \mu \mathrm{m}$, whereas in subgroup IVB was $78.50 \pm 45.96 \mu \mathrm{m}$. There was a statistically significant difference between the two subgroups, with a decrease in lesion depth in subgroup IVB $(P<0.001)$. Percent difference between NHA test group (IIIB) and its control group (IIIA) was -58.96 \pm 9.04, whereas the percent difference between fluoridated toothpaste test group (IVB) and its control (IVA) was $56.26 \pm 17.43$. There was no statistically significant difference between the two values $(P=0.67)$ (Table 3).

Qualitative results of polarized light microscope showed improvement of the caries-like lesions after application of toothpastes. This was observed in the enamel of both subgroups IIIB and IVB specimens. Most of the representative lesions showed marked reduction in the depth of the carious lesion compared to subgroups IIIA and IVA. Other specimens showed noticeable degree of remineralization. This was observed through the restoration of Hunter-Schreger bands emphasizing the effect of these toothpastes in remineralization (Figure 3).

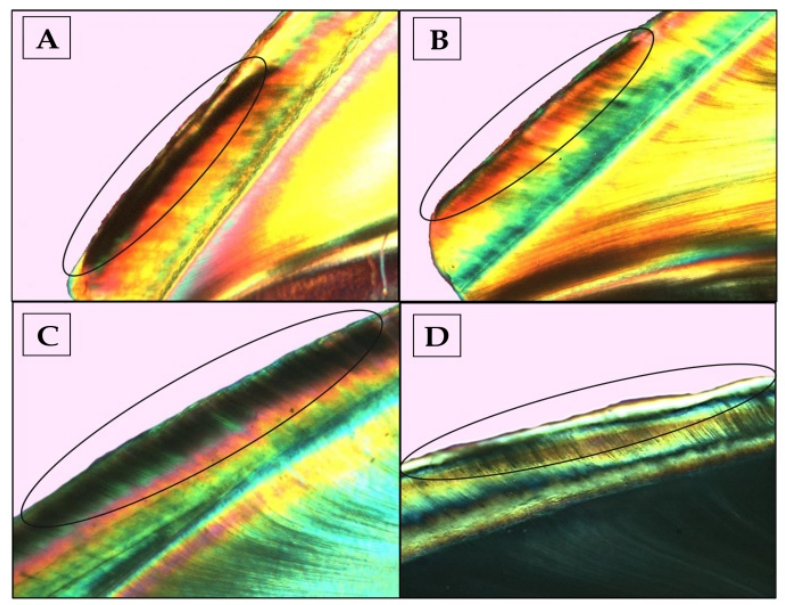


Figure 3:Polarized light photomicrograph of longitudinal ground sections of one of each group showing (A): a specimen of the NHA control group (subgroup IIIA) showing a well-developed dark demineralized band of enamel, magnification X40, (B): a specimen treated with NHA (subgroup IIIB) showing complete homogenous extensive remineralization of the caries like lesion, (c): fluoridated toothpaste control specimen (subgroup IVA) showing a well-developed dark demineralized band of enamel, (D): a specimen treated with fluoridated toothpaste (subgroup IVB) showing decrease in the extent of the lesion

Table 1: Vickers microhardness values of studied groups across the time.

\begin{tabular}{||l|l|l|}
\hline \multirow{2}{*}{$\begin{array}{l}\text { Microhardness } \\
\text { across Time }\end{array}$} & Mean \pm SD \\
\cline { 2 - 3 } & NHA Toothpaste & $\begin{array}{l}\text { Fluoridated } \\
\text { Toothpaste }\end{array}$ \\
\hline Baseline & $286.47 \pm 29.12$ & $285.78 \pm 27.55$ \\
\hline $\begin{array}{l}\text { After } \\
\text { demineralization }\end{array}$ & $257.85 \pm 29.01$ & $257.13 \pm 29.77$ \\
\hline After toothpaste use & $277.45 \pm 27.85$ & $272.43 \pm 26.53$ \\
\hline
\end{tabular}

Table (2): Effect of toothpaste type on percent change in microhardness and adjusted means for percent change

\begin{tabular}{||l|l|l|}
\hline \multicolumn{1}{|l|}{} & $\begin{array}{l}\text { NHA } \\
\text { toothpaste }\end{array}$ & $\begin{array}{l}\text { Fluoridated } \\
\text { toothpaste }\end{array}$ \\
\hline B (95\% CI) & $1.65(-0.06,3.35)$ \\
\hline P Value & 0.06 & \\
\hline Adjusted mean & 7.80 & 6.16 \\
\hline Standard error & 0.59 & 0.59 \\
\hline $95 \%$ CI & $6.60,9.01$ & $4.96,7.36$ \\
\hline
\end{tabular}

B: Regression coefficient

CI: Confidence interval

*statistically significant at $p$ value $\leq 0.05$

Adjusted R2=0.37, $\mathrm{F}=12.59$, $\mathrm{P}$ value $<0.001 *$

Model was adjusted for baseline microhardness values

Table (3): Lesion depth values of all studied groups and percent difference between each test and its control group

\begin{tabular}{|c|c|c|c|c|c|}
\hline \multirow{2}{*}{\multicolumn{2}{|c|}{ Lesion depth }} & \multicolumn{2}{|c|}{$\begin{array}{l}\text { NHA Toothpaste } \\
\text { (group III) } n=20\end{array}$} & \multicolumn{2}{|c|}{$\begin{array}{r}\text { Fluoridated } \\
\text { Toothpaste } \\
\text { (group III) n=20 } \\
\end{array}$} \\
\hline & & $\begin{array}{r}\text { Subgroup } \\
\text { IIIA } \\
\text { (untreate } \\
\text { d) } \mathbf{n = 1 0}\end{array}$ & $\begin{array}{r}\text { Subgrou } \\
\text { p IIIB } \\
\text { (treated) } \\
\mathbf{n = 1 0}\end{array}$ & $\begin{array}{r}\text { Subgroup } \\
\text { IVA } \\
\text { (untreate } \\
\text { d) } \mathbf{n = 1 0}\end{array}$ & $\begin{array}{r}\text { Subgrou } \\
\text { p IVB } \\
\text { (treated) } \\
\mathbf{n = 1 0}\end{array}$ \\
\hline \multicolumn{2}{|c|}{ Mean \pm SD } & $\begin{array}{r}191.70 \pm \\
50.87 \mu \mathrm{m}\end{array}$ & $\begin{array}{r}77.30 \pm \\
22.61 \\
\mu \mathrm{m} \\
\end{array}$ & $\begin{array}{r}172.30 \pm \\
57.28 \mu \mathrm{m}\end{array}$ & $\begin{array}{r}78.50 \pm \\
45.96 \mu \mathrm{m}\end{array}$ \\
\hline \multicolumn{2}{|l|}{ Paired t } & \multicolumn{2}{|l|}{9.19} & \multicolumn{2}{|l|}{7.80} \\
\hline \multicolumn{2}{|l|}{$\mathrm{P}$ value } & \multicolumn{2}{|l|}{$<0.001 *$} & \multicolumn{2}{|l|}{$<0.001 *$} \\
\hline \multirow{3}{*}{$\begin{array}{l}\text { Percent } \\
\text { differenc } \\
\text { e }\end{array}$} & $\begin{array}{l}\text { Mean } \pm \text { S } \\
\text { D } \\
\end{array}$ & \multicolumn{2}{|c|}{$-58.96 \pm 9.04$} & \multicolumn{2}{|c|}{$-56.26 \pm 17.43$} \\
\hline & t test & \multicolumn{4}{|l|}{0.44} \\
\hline & P value & \multicolumn{4}{|l|}{0.67 (NS) } \\
\hline
\end{tabular}

Statistically non-significant (NS)

\section{DISCUSSION}

In this study, nano hydroxyapatite toothpaste was compared to fluoridated toothpaste $(1450 \mathrm{ppm})$ to evaluate their remineralizing effect on pre-cavitated carious lesion. The results were in favor of the null hypothesis, where NHA toothpaste and fluoridated one had a similar positive effect on enamel remineralization when applied to the teeth after the acidic challenge. Thus proving their therapeutic effect on lesion formed after demineralization in which surface microhardness increased and lesion depth decreased when compared to before application of toothpastes.

In recent years NHA has been generally accepted in dentistry and medicine as it is recognized among the most bioactive and biocompatible materials (24). Nanohydroxyapatite shows strong affinity to the tooth, and can be strongly adsorbed on enamel surface. Nanohydroxyapatite toothpaste is used as a new technique for prevention and remineralization of caries (25).

Teeth were soaked in a standardized demineralizing solution to mimic the demineralized stage that could typically occur in the structure of the tooth and create a generalized baseline for the various specimens instead of using carious teeth that would have varying demineralization levels. So an intermediate $\mathrm{pH}$ solution (4.2) was used for 96 hours (19).

In the present study, the effect of NHA on enamel remineralization was assessed by evaluating its effect on surface microhardness using Vickers microhardness tester. Vickers microhardness tester was chosen in the present study because measurement is more accurate and easier (26). The teeth after treatment showed a higher surface microhardness values by about $8 \%$ in comparison to after demineralization. Likewise, the results of lesion depth revealed the ability of NHA toothpaste to enhance enamel remineralization in the treated teeth in which lesion depth was about $60 \%$ lower than that of untreated specimens. In line with these results, Huang et al (2009) (27), evaluated the impact of nanohydroxyapatite-containing toothpastes on initial enamel lesions under complex $\mathrm{pH}$ cycling conditions in which the study results have concluded that NHA has the ability to remineralize initial enamel lesions.

Fluoridated toothpaste was regarded as a control because it is among the most studied preparations. In addition, it is recommended by the WHO and the American Academy of Pediatric Dentistry (AAPD) $(28,29)$ for children younger than 6 years due to its proved efficacy in remineralizing dental caries in high caries risk children. Fluoridated toothpaste was also tested in the current study and the results showed its ability in remineralization. Mean microhardness value of the teeth after treatment was about $6 \%$ higher than that after demineralization and the depth of the lesion in treated specimens was 54\% lower than that of untreated specimens.

Qualitative evaluation was performed by polarized light microscope to evaluate the zones of caries like lesions. It was noted in all treated specimens in both groups that the lesions had less depth in comparison with the negative control specimens, and that the quality of the lesions appeared different in the treated specimens, as most of the treated specimens showed a highly mineralized surface layer that wasn't evident in the non-treated specimens. This is mostly attributed to the effect of the remineralizing agents 
provided by both treatment materials on the specimens' surface.

Despite the fluoride's global cariostatic therapeutic effect (30), a long debate was observed in the literature regarding the anticaries effect of low-fluoride toothpastes (e.g. $500 \mathrm{ppm} \mathrm{F}$ ) prescribed for children (31). Some may recommend increasing the dosage of fluoride as its effectiveness is dosage-dependent (32), however, there is a limit to the dose of fluoride permitted in oral care products to avoid the risk of fluorosis in children (33).

The NHA toothpaste showed a therapeutic capacity that is comparable to the fluoridated toothpaste. This is evident by the study results, which proved both NHA and fluoridated toothpaste were effective in increasing remineralization of primary enamel with no significant difference even though the NHA showed a higher percentage of microhardness variation and difference in lesion depth. Similarly, Schlagenhauf et al (2019) (34) showed that the effect of the daily usage of a NHA dentifrice on the development of caries in extremely caries-active patients does not differ significantly from the use of $1400 \mathrm{ppm}$ of fluoride toothpaste. On the other hand, Ebadifar et al (2017) (10) compared effect of toothpaste containing NHA and fluoride and toothpaste containing fluoride alone on remineralization using Vickers microhardness tester to measure microhardness. It was concluded that the toothpaste containing NHA was more effective in remineralization than the NHA free toothpaste.

The limitations of this study were the difficulty in reproducing the oral environment including the biofilm and oral flora, different salivary components, individuals eating habits and oral hygiene practices. In addition, the present study was limited to a period of 15 days of toothpaste application after 4 days of demineralization, while the de/remineralization processes are long-term processes.

In conclusion, the present results support the remineralizing effect of NHA toothpaste; however, further studies are recommended to evaluate the oral factors and the anti-microbial potential of the toothpaste.

\section{CONCLUSIONS}

Based on the results of this in vitro study, it was concluded that:

Both nano hydroxyapatite and fluoridated toothpastes are equally effective as remineralizing materials that can remineralize pre-cavitated lesions caused by cariogenic challenge in primary teeth.

Both tested materials were not able to return to surface microhardness before demineralization.

Nano hydroxyapatite toothpaste could be used as an alternative to fluoridated toothpaste in children with high caries risk.

\section{CONFLICT OF INTEREST}

The authors declare that they have no conflicts of interest.

\section{FUNDING}

This research received no specific grant from any funding agency in the public, commercial, or not-for-profit sectors.

\section{REFERENCES}

1. Pitts NB, Zero DT, Marsh PD, Ekstrand K, Weintraub JA, Ramos-Gomez F, et al. Dental caries. Nat Rev Dis Primers. 2017;3:17030.

2. Fejerskov O, Kidd EAM. Dental caries: the disease and its clinical management. Oxford, Ames, Iowa: Blackwell Munksgaard; 2008.

3. Horst JA, Tanzer JM, Milgrom PM. Fluorides and Other Preventive Strategies for Tooth Decay. Dent Clin North Am. 2018;62:207-34.

4. Philip N. State of the Art Enamel Remineralization Systems: The Next Frontier in Caries Management. Caries Res. 2019;53:284-95.

5. Larsen MJ, Richards A. Fluoride is unable to reduce dental erosion from soft drinks. Caries Res. 2002;36:75-80.

6. Pajor K, Pajchel L, Kolmas J. Hydroxyapatite and Fluorapatite in Conservative Dentistry and Oral Implantology-A Review. Materials (Basel). 2019;12:2683.

7. Thimmaiah C, Shetty P, Shetty SB, Natarajan S, Thomas NA. Comparative analysis of the remineralization potential of CPP-ACP with Fluoride, Tri-Calcium Phosphate and Nano Hydroxyapatite using SEM/EDX - An in vitro study. J Clin Exp Dent. 2019;11:e1120-6.

8. Pepla E, Besharat LK, Palaia G, Tenore G, Migliau G. Nano-hydroxyapatite and its applications in preventive, restorative and regenerative dentistry: a review of literature. Ann Stomatol (Roma). 2014;5:108-14.

9. Haghgoo R, Mehran M, Ahmadvand M. Remineralization Effect of Eggshell versus Nanohydroxyapatite on Caries-like Lesions in Permanent Teeth (In Vitro). Int Oral Heal. 2016;8:435-9.

10. Ebadifar A, Nomani M, Fatemi SA. Effect of nanohydroxyapatite toothpaste on microhardness ofartificial carious lesions created on extracted teeth. J Dent Res Dent Clin Dent Prospects. 2017;11:14-7.

11. Charan J, Biswas T. How to calculate sample size for different study designs in medical research? Indian J Psychol Med. 2013;35:121-6.

12. Daniel WW. Biostatistics. A foundation for analysis in the health science. $6^{\text {th }}$ ed. New York: John Wiley and sons, Inc; 1995.

13. Pannucci CJ, Wilkins EG. Identifying and Avoiding Bias in Research. Plast Reconstr Surg. 2010;126:619-25.

14. Faul F, Erdfelder E, Lang AG, Buchner A. G*Power 3: A flexible statistical power analysis program for the social, behavioral, and biomedical sciences. Behav Res Methods. 2007;39:175-91.

15. Nozari A, Ajami S, Rafiei A, Niazi E. Impact of nano hydroxyapatite, nano silver fluoride and sodium fluoride varnish on primary enamel remineralization: An in vitro study. J Clin Diagnostic Res. 2017;11:ZC97-100.

16. De Gauw JH, Costa LM, Silva RN, Santos NB, Tenorio MD. Evaluation of the Effect of Ferrous Sulfate on Enamel Demineralization of Human 
Deciduous Teeth: an in Vitro Study. Bahiana J Odontol 2017;8:83-9.

17. Mohammadi N, Farahmand Far MH. Effect of fluoridated varnish and silver diamine fluoride on enamel demineralization resistance in primary dentition Najmeh. J Indian Soc Pedod Prev Dent. 2018;36:257-61.

18. Duggal M, Toumba K, Amaechi B, Kawash M, Higham S. Enamel demineralization in situ with various frequencies of carbohydrate consumption with and without fluoride toothpaste. J Dent Res. 2001;80:1721-4.

19. Kiranmayi M, Nirmala SVS, Nuvvula S. Appraisal of the remineralizing potential of child formula dentifrices on primary teeth: An in vitro $\mathrm{pH}$ cycling model. Contemp Clin Dent. 2015;6:S81-5.

20. Gavic L, Gorseta K, Borzabadi-Farahani A, Tadin A, Glavina D. Influence of toothpaste $\mathrm{pH}$ on its capacity to prevent enamel demineralization. Contemp Clin Dent 2018;9:554-9.

21. Haghgoo R, Ahmadvand M, Moshaverinia S. Remineralizing Effect of Topical NovaMin and Nanohydroxyapatite on caries-like Lesions in Primary teeth. J Contemp Dent Pract. 2016;17:645-9.

22. De Campos PH, Sanabe ME, Rodrigues JA, Duarte DA, Santos MTBR, Guaré RO, et al. Different bacterial models for in vitro induction of noncavitated enamel caries-like lesions: Microhardness and polarized light miscroscopy analyses. Microsc Res Tech. 2015;78:444-51.

23. Tornqvist L, Vartia P, Vartia YO. How Should Relative Changes Be Measured? Am Stat. 1985;39:43-6.

24. Tschoppe P, Zandim DL, Martus P, Kielbassa AM. Enamel and dentine remineralization by nanohydroxyapatite toothpastes. J Dent. 2011;39:430-7.
25. Najibfard K, Ramalingam K, Chedjieu I, Amaechi B. Remineralization of early caries by a nanohydroxyapatite dentifrice. J Clin Dent. 2011;22:13943.

26. Chuenarrom C, Benjakul P, Daosodsai P. Effect of Indentation Load and Time on Knoop and Vickers Microhardness Tests for Enamel and Dentin. Mater Res. 2009;12:473-6.

27. Huang SB, Gao SS, Yu HY. Effect of nanohydroxyapatite concentration on remineralization of initial enamel lesion in vitro. Biomed Mater. 2009;4:034104.

28. O’Mullane DM, Baez2 RJ, Jones S, Lennon MA, Petersen PE, RuggGunn AJ, et al. Fluoride and oral health. Community Dent Health. 2016;33:69-99.

29. American Academy on Pediatric Dentistry Council on Clinical Affairs. Policy on the use of xylitol in caries prevention. Pediatr Dent. 2008;30:36-7.

30. Buzalaf MAR, Pessan JP, Honorio HM, Ten Cate JM. Mechanisms of action of fluoride for caries control. Monogr Oral Sci. 2011;22:97-114.

31. Cury JA, Tenuta LMA. Evidence-based recommendation on toothpaste use. Braz Oral Res. 2014;28:1-7.

32. Walsh T, Worthington HV, Glenny AM, Marinho VC, Jeroncic A. Fluoride toothpastes of different concentrations for preventing dental caries. Cochrane database Syst Rev. 2019;3:CD007868.

33. Zohoori FV, Maguire A. Are there good reasons for fluoride labelling of food and drink? England: British dental journal; 2018. pp. 215-7.

34. Schlagenhauf U, Kunzelmann KH, Hannig C, May TW, Hösl H, Gratza M, et al. Impact of a nonfluoridated microcrystalline hydroxyapatite dentifrice on enamel caries progression in highly caries-susceptible orthodontic patients: A randomized, controlled 6-month trial. J Investig Clin Dent. 2019;10:e12399-9. 